\title{
Behaviour and therapeutic itinerary of epileptic patients in Marrakech city and surrounding regions in South Morocco
}

\author{
Abdelaati El Khiat ${ }^{1,2^{*}}$, Najib Kissani ${ }^{3^{*}}$, Abdellatif Abbaoui ${ }^{1}$, Mohamed Chraa ${ }^{3}$, Mohamed Loukid ${ }^{4}$, \\ Halima Gamrani ${ }^{1}$ and Mohamed Kamal Hilali ${ }^{4}$
}

\begin{abstract}
Background: Epilepsy is a chronic, universal disorder with various etiologies and prognoses. It is still laden with myths in the majority of the Moroccan population. Despite the existence of well-established medicinal treatments and increasingly comprehensive care, access to antiepileptic care is still limited, especially for rural populations. We aim herein to identify the therapeutic itinerary of patients with epilepsy (or epileptic disorders) as well as the behaviour of patients and their families towards this disease in Marrakech and the surrounding region of Marrakech-Safi.

Methods: We carried out a retrospective study Questionnaire filled by 110 patients data was analysed with SPSS version 18.

Results: Our results showed that $69.96 \%$ of the patients believed in a supernatural origin of the disease and $76.4 \%$ attended for professional medical care after their first seizure. In addition, more than half of our patients (51.8\%) consulted a religious leader for the initial consultation, $51.0 \%$ of whom were women and $49.0 \%$ were male. The low socioeconomic status of patients with epilepsy, $74.5 \%$ of whom were unemployed, impeded the effective management of this disease.

Conclusions: These results suggest that the management of patients with epilepsy (or epileptic disorders) in Africa, and particularly in Morocco requires, in addition to the reinforcement of human and material resources, an effort to educate and positively influence the family and the social environment as a whole.
\end{abstract}

Keywords: Beliefs, Epilepsy, Marrakech and south of Morocco, Seizures, Therapeutic itinerary

\section{Background}

Epilepsy is a chronic neurological disorder with various etiologies and prognoses [1,2], characterized by the repetition of spontaneous epileptic seizures [3]. This universal and ubiquitous condition remains very poorly understood in Morocco [4]. Clinical manifestations of epilepsy

\footnotetext{
*Correspondence: abdelaatielkhiat@gmail.com; najibkis@gmail.com

${ }^{2}$ Higher Instituate of Nursing Professions and Health Techniques, Ministry of Health, B.P. 45000 Ouarzazate, Morocco

${ }^{3}$ Neurology Department, University Hospital Mohammed VI, Principal، Avenue Ibn Sina, B.P. 2360 Marrakech, Morocco

Full list of author information is available at the end of the article
}

are numerous, varied and allow us to define not epilepsy, but epilepsies according to the type of the generalized or partial seizure and the etiology (symptomatic, cryptogenic or idiopathic) [5]. It is a very common neurological disorder that affects more than 50 million people worldwide [6], including 10 million in Africa [2]. In Morocco, nearly 374,000 people are epileptic according to a study carried out in Casablanca [7]. The prevalence in the Western countries is between 0.5 and $0.8 \%$, whereas in developing countries it ranges from 1 to $5 \%$. The prevalence in Morocco is $1.1 \%$ [8, 9] and unfortunately still appears to the public as a shameful, dishonourable and 
supernatural illness. Despite the existence of well-established drug treatments and increasingly comprehensive care, access to antiepileptic care is still limited, especially for rural populations [10-12].

Studies interested in the behavior and therapeutic itinerary of epileptic patients especially in underdeveloped countries such as Morocco are still rare until recently. From this point of view, this study aim to better understand the different stages of an epileptic patient's behaviour and management of their condition. As we know, this was the first study in Morocco. It was carried out in the region of Marrakech city, suburban region and province, and was interested in the interaction of socioeconomic, cultural and behavioural factors in epileptic patients, in order to identify the therapeutic itinerary of epileptic patients in the Marrakech city and its region.

\section{Methods}

This retrospective study was conducted in the Neurology Department of the Ibn Tofail Hospital of the Mohammed VI University Hospital in Marrakech during the period between March 2016 and July 2016. The study was carried out in the Marrakech-Safi region at the University Hospital Center (CHU), which drains the entire population of southern Morocco.

\section{Patients and questionnaire}

The survey covered 110 patients of both sexes who attended a consultation for epilepsy. After given detailed explanation of the objectives of this study, the participants were interviewed epilepsy face-to-face in local language (Arabic or Berber) and/or French according to their own choice. They were subjected to a questionnaire, which divided into two parts containing closed and open questions. The first part included Socio-economic characteristics; and demographic and cultural characteristics of patients, including age, gender, marital status, level of education, occupational activity, parental education level, etc. The second part contained a set of information on the therapeutic itinerary of the patients, as well as their behavior and those of their family members with regard to epilepsy. The questionnaires were completed by epileptic patients and/or their parents. All the participants met the inclusion and exclusion criteria as follows. Inclusion criteria: the presence of epilepsy in patients (at any age and for both genders) according to a clinical assessment by a neurologist and neuropsychologist; and being under pharmacological treatment; and with or without abnormalities in EEG examination. Exclusion criteria: any patients without clinical confirmation as epilepsy (with a first consultation) were excluded.

\section{Statistical analysis}

The data was collected and processed by Statistical Package for the Social Sciences (SPSS, version 18). For qualitative variables, the frequencies of their components were used to observe the distribution in population. To further illustrate the impact of the different confounding factors and to highlight the weight of each of the explanatory variables retained on the dependent variable, the consulting seeking behavior, A bivariate analysis was performed first to see the association between some variables and the therapist and second we applied the binary logistic regression model (OR and $95 \% \mathrm{CI}$ ) (Table 4), keeping the variables significant in univariate.

\section{Results}

Demographic and socio-cultural characteristics of epileptic patients

We conducted a retrospective study involving 110 people who attended for a consultation of epilepsy in the Department of Neurology at the University Hospital Center (CHU Mohammed VI, Marrakech), Ibn Tôfail Hospital between March 2016 and July 2016. These patients were comprised of 56 males $(50.9 \%)$ and 54 females $(49.1 \%)$. The age varied between 4 and 80 years with a mean age of $30.97 \pm 16.04$ years. The mean age of males was $28.7 \pm 16.9$ years and that of females was $33.24 \pm 15.7$ years.

Of the 110 individuals surveyed, $65.5 \%$ were single, $74.9 \%$ were unemployed, $52.7 \%$ had an average level of education (between 7 and 9 years of education), and $25.80 \%$ had another family member with epilepsy, of whom $50 \%$ were cousins or uncles. Most parents surveyed were illiterate $(47.4 \%)$. The details of the age distribution, marital status, occupation, education (of patients and their parents) and epileptics in the surveyed family are presented in Table 1.

\section{Behaviour and therapeutic itinerary}

In the whole study group, a belief in a supernatural origin (devils, evil eye, bewitching, divine trial) of the condition was found in $69.96 \%$. Of the subjects surveyed, the age of the first seizure varied from birth to 67 years with an average onset of $15.47 \pm 15.21$ years (range 0-67 years). Almost half (48.02\%) had their first seizure between birth and 10 years, and $76.4 \%$ attended for a professional medical consultation at least once after their first seizure. Moreover, more than half of the patients $(51.8 \%)$ firstly consulted a religious leader after their first seizure, of whom $51.0 \%$ were women and $49.0 \%$ were men. Nearly half $(44.5 \%)$ of the reason given for consultations were a family decision. The 
Table 1 Demographic and socio-cultural characteristics of patients with epilepsy $(N=110)$

\begin{tabular}{|c|c|}
\hline Variables & $N$ (frequency \%) \\
\hline \multicolumn{2}{|l|}{ Sex } \\
\hline Male & $56(50.9)$ \\
\hline Female & $54(49.1)$ \\
\hline \multicolumn{2}{|l|}{ Age distribution } \\
\hline $0-15$ & $14(12.7)$ \\
\hline $16-30$ & $50(45.5)$ \\
\hline $31-45$ & $27(24.5)$ \\
\hline $46-60$ & $13(11.8)$ \\
\hline$>61$ & $6(5.5)$ \\
\hline \multicolumn{2}{|l|}{ Marital status } \\
\hline Single & $72(65.5)$ \\
\hline Married & $31(28.2)$ \\
\hline Divorced or widowed & $7(6.3)$ \\
\hline \multicolumn{2}{|l|}{ Level of education } \\
\hline Low level instruction ${ }^{a}$ & $36(32.7)$ \\
\hline Average level ${ }^{\mathrm{b}}$ & $58(52.7)$ \\
\hline Higher level $^{c}$ & $16(14.5)$ \\
\hline \multicolumn{2}{|l|}{ Epileptics in the family of respondents } \\
\hline Children & $4(14.2)$ \\
\hline Parents & $5(17.9)$ \\
\hline $\begin{array}{l}\text { Siblings } \\
\text { Cousin-uncle }\end{array}$ & $\begin{array}{l}5(17.9) \\
14(50.0)\end{array}$ \\
\hline \multicolumn{2}{|l|}{ Education level of parents } \\
\hline The two illiterates & $45(47.4)$ \\
\hline One of the two educated & $16(16.8)$ \\
\hline The two educated & $34(35.8)$ \\
\hline \multicolumn{2}{|l|}{ Socio-professional } \\
\hline Unemployed patients & $40(36.4)$ \\
\hline Housewives & $21(19.1)$ \\
\hline Students & $18(16.4)$ \\
\hline Officials and liberal professions & $11(10.0)$ \\
\hline Workers or Executing Agents & $17(15.5)$ \\
\hline Retired & $3(2.6)$ \\
\hline
\end{tabular}

${ }^{a}$ Low level (illiterate) and Koranic

${ }^{\mathrm{b}}$ Average level (Primary and secondary school: between 7 and 9 years of education)

' Higher-level (High school, university and postgraduate: more than 9years of education)

details of patients' beliefs about the origin of epilepsy, age of first seizure, and initial consultation are presented in Table 2 .

\section{Socio-demographic and cultural characteristics of the first consultant}

According to the results appearing in Table 3, there is a statistically association between the first consultant and the age group of the patients $\left(\chi^{2}=9.62 ; p=0.047\right)$. In addition, there is a non-significant relationship between
Table 2 Behaviour and therapeutic itinerary of patients with epilepsy

\begin{tabular}{ll}
\hline Variables & $\boldsymbol{N}$ (Frequency \%) \\
\hline Patients' beliefs about the origin of epilepsy & \\
$\quad$ Natural Disease & $31(28.2)$ \\
Supernatural & $70(69.96)$ \\
$\quad$ No opinion & $9(8.2)$ \\
Onset age & \\
$0-10$ & $53(48.02)$ \\
$11-30$ & $40(36.4)$ \\
$31-50$ & $11(10.0)$ \\
$>51$ & $6(5.5)$ \\
First consultation & \\
Traditional healers & $57(51.8)$ \\
Male nurse & $4(3.7)$ \\
General Practitioner & $48(43.6)$ \\
Pharmacy & $1(0.9)$ \\
\hline
\end{tabular}

the first consultant and the parents' level of education $\left(x^{2}=2.346 ; p=0.310\right)$ and with the professional activity of the patients, the chi-square test shows that there is a relationship of dependence between the groups $\left(x^{2}=16.10 ; p=0.006\right)$. Indeed, unemployed patients, housewives, workers or executing agents are associated with the traditional consultant and the others no longer consult the (modern) doctor.

Finally, to test the role of the most significant variable, which is the consequence, and to highlight the weight of each of the variables studied on the choice of first consultant, we performed a binary logistic regression analysis (Table 4). In fact, analysis of the relationship between the first consultant and the patient's age group shows a greater number of first consultations with a general practitioner in cases where the age groups of the patients were [0-15 years]. Similarly, there was also a no statistically significant association between the other age groups (range 16-60 years) and their first consultation being with a traditional healer $(p=0.184$, Table 4$)$. The study of the relationship between the first consultant and the patient profession shows that there is a non-significant relationship $(p=0.124)$. We observed a greater number of first consultations were with a traditional healer among the unemployed, housewives and manual workers or delivery agents. Moreover, in students public servants we observed a greater number of first consultations were with a general practitioner (Table 4). The study also showed a non-significant relationship between the parents' level of education and the type of first consultation and between both parents being illiterate, the first consultation being with a traditional healer, and 
Table 3 The relationship between the first consultant and socio-demographic and cultural characteristic in patients with epilepsy

\begin{tabular}{|c|c|c|c|c|c|}
\hline \multirow[t]{2}{*}{ Variables } & \multirow[t]{2}{*}{ Modality } & \multicolumn{2}{|c|}{ First consultant $N$} & \multirow[t]{2}{*}{$x^{2}$ test } & \multirow[t]{2}{*}{$P$ value } \\
\hline & & Traditional & Modern & & \\
\hline \multirow{3}{*}{$\begin{array}{l}\text { Education level of the patients' } \\
\text { parents }\end{array}$} & The two illiterates & 25 & 20 & \multirow[t]{3}{*}{2.346} & \multirow[t]{3}{*}{0.310} \\
\hline & One of the two educated & 9 & 7 & & \\
\hline & The two educated & 13 & 21 & & \\
\hline \multirow[t]{5}{*}{ Age distribution } & $0-15$ & 2 & 12 & \multirow[t]{5}{*}{9.62} & \multirow[t]{5}{*}{0.047} \\
\hline & $16-30$ & 28 & 22 & & \\
\hline & $31-45$ & 17 & 10 & & \\
\hline & $46-60$ & 7 & 6 & & \\
\hline & $>60$ & 3 & 3 & & \\
\hline \multirow[t]{6}{*}{ Occupation of patients } & Unemployed patients & 24 & 16 & \multirow[t]{6}{*}{16.155} & \multirow[t]{6}{*}{0.006} \\
\hline & Students & 3 & 15 & & \\
\hline & Housewives & 13 & 8 & & \\
\hline & Officials and liberal professions & 3 & 8 & & \\
\hline & Workers or Executing Agents & 12 & 5 & & \\
\hline & Retired & 2 & 1 & & \\
\hline
\end{tabular}

Table 4 Variables of the model of binary logistic regression and socio-demographic and cultural characteristics associated with to first consultants

\begin{tabular}{|c|c|c|c|c|c|}
\hline Variant & $N=110$ & $\begin{array}{l}\text { consult with } \\
\text { religious guide }\end{array}$ & $\begin{array}{l}\text { not consult with } \\
\text { religious guide }\end{array}$ & OR $(95 \% \mathrm{Cl})$ & $p$-value \\
\hline Education of patients' parents & & & & & 0.310 \\
\hline The two illiterates & 45 & $25(54.3 \%)$ & $20(44.4 \%)$ & Ref. & \\
\hline One of the two educated & 16 & $8(50.0 \%)$ & $8(50.0 \%)$ & $2.088(0.326-3.247)$ & \\
\hline The two educated & 34 & $12(35.3 \%)$ & $22(64.7 \%)$ & $1.513(0.174-1.091)$ & \\
\hline Age distribution & & & & & 0.184 \\
\hline $0-15$ & 14 & $2(14.3 \%)$ & $12(87.5 \%)$ & Ref. & \\
\hline $16-30$ & 50 & $28(56.0 \%)$ & $22(44.0 \%)$ & $0.113(0.016-0.779)$ & \\
\hline $31-45$ & 27 & $17(63.0 \%)$ & $10(37.0 \%)$ & $0.106(0.014-0.822)$ & \\
\hline $46-60$ & 13 & $7(53.8 \%)$ & $6(46.2 \%)$ & $0.065(0.005-0.878)$ & \\
\hline$>61$ & 6 & $3(50.0 \%)$ & $3(50.0)$ & $0.022(0.000-1.130)$ & \\
\hline Occupation of patients & & & & & 0.124 \\
\hline Unemployed patients & 40 & $24(60.0 \%)$ & $16(40.0 \%)$ & Ref. & \\
\hline Housewives & 21 & $13(61.9 \%)$ & $8(38.1 \%)$ & $0.919(0.258-3.276)$ & \\
\hline Students & 18 & $3(16.7 \%)$ & $15(83.3 \%)$ & $4.041(0.863-18.921)$ & \\
\hline Officials and liberal professions & 11 & $3(27.3 \%)$ & $8(72.7 \%)$ & $4.721(0.963-23.142)$ & \\
\hline Workers or Executing Agents & 17 & $12(70.6 \%)$ & $5(29.4 \%)$ & $0.738(0.186-2.925)$ & \\
\hline Retired & 3 & $2(66.7 \%)$ & $1(33.3 \%)$ & $0.111-15.960$ & \\
\hline Age at first seizure & & & & & 0.031 \\
\hline $0-10$ & 53 & $32(60.4 \%)$ & $21(39 . \%)$ & Ref. & \\
\hline $11-30$ & 40 & $19(47.5 \%)$ & $21(52.5 \%)$ & $2.773(0.954-8.065)$ & \\
\hline $31-50$ & 11 & $5(45.5 \%)$ & $6(54.5 \%)$ & $5.925(1.025-34.261)$ & \\
\hline$>50$ & 6 & $1(16.7 \%)$ & $5(83.3 \%)$ & $48.241(1.821-1278.293)$ & \\
\hline
\end{tabular}

OR odds ratio; $\mathrm{Cl}$ confidence interval

between both parents being educated and the first consultation being with a general practitioner $(p=0.310)$. Also, analysis of the relationship between the first consultant and the age at first crisis shows a significant relationship $(p=0.031)$ (Table 4$)$. The first seizure age of young people risks traditional consultation and that 
above 10 years the tendency is towards a consultation of the modern therapist.

\section{Discussion}

As far as we know, this is the first study interested in the behaviour and therapeutic itinerary of epileptic patients in Marrakech city and its region.

The study of professional activity demonstrated that only $25.5 \%$ were employed at the time of the survey, while $74.5 \%$ were not, this rate of unemployment is relatively close to that recorded in the city of Oujda (69.1\%) [13] and in Mauritania (70.7\%) [14]. Regarding educational level, our results showed that the educational level of our patients is relatively average. The illiteracy rate or low level calculated for our sample (32,7\%) is lower than that found in the city of Oujda (51.4\%) [13], Marrakech (41\%) [15] and Tangier (55.60\%) [13]. This lower illiteracy rate observed in our study is an indicator of the importance of family and epilepsy associations in the overall management of epileptic patients.

Concerning patients' beliefs about the origin of epilepsy, $69.96 \%$ of patients respondents in our sample believe in a supernatural origin of the disease: devils (Jinns), evil eye (Al Ayne), bewitching (Assihar), or divine trial (Al Kadar). This result is consistent with studies carried out in Oujda, the oriental city of Morocco, showing $68.1 \%$ [13] and $45.7 \%$ in the capital city and its region Rabat-Salé-Zemmour-Zaer [16]. The notion of a supernatural origin of epilepsy is also found in studies carried out by other developing countries, such as Senegal [17], the Central African Republic [18], and Mauritania [14]. This ancient belief evolved over time, and was more pronounced in traditional composite societies [19]. Of all the patients studied, $76.4 \%$ underwent a professional medical consultation after their first seizure; whereas $23.6 \%$ of patients had their first consultation after a number of repetitive seizures. The fact that majority of identified epileptics were treated after their first seizure, demonstrated the importance the family attached to the healing and mental health of the patient. Moreover, $51.8 \%$ patients consulted traditional healers (traditional herbalists or in religious leaders) after the first seizure, of whom $51.0 \%$ are women and $49.0 \%$ are men. For $44.5 \%$ of these consultants, the reason for this choice was a family decision. This behaviour derives from the socio-cultural representations of this condition in Moroccan society. This result is relatively similar to that found in the Rabat-Salé-Zemmour-Zaer region (48.2\%) [16] and Tangier region (46.7\%) [13] moreover, $16.6 \%$ of a Cameroonian population studied also consulted religious leaders [20].

\section{Conclusion}

Epilepsy is still a public health problem in developing countries and especially in Morocco.This retrospective study revealed the profile of epileptic patients in Marrakech city, the suburban region and province. A significant percent of patients studied, despite the small sample size, believed in a supernatural origin of the disease. Illogical beliefs, as evidenced by the results of this study still prevail in the region of Marrakech. The management of the condition was usually after the first seizure, and traditional healers were the first resort for numerous patients.

\section{Abbreviations \\ SPSS: Statistical Package for the Social Sciences; CHU: University Hospital Center.}

\section{Acknowledgements}

We thank all physicians of the neurology department team of Marrakech for their contribution in the study.

We thank all the patients with epilepsy and their family for their wiliness to participate in this study.

We thank Dr. Peter Garland, from gateway association, in Marrakech for his help in English revising of the paper.

\section{Authors' contributions}

Abdelaati El Khiat1, 2*, Najib Kissani3, Abdellatif Abbaoui1, Mohamed Chraa3, Mohamed Loukid4, Halima Gamrani1, Mohamed Kamal Hilali4. The author(s) read and approved the final manuscript.

\section{Funding}

Not applicable.

Availability of data and materials

All data generated or analyzed in this study are included in this manuscript and its additional files.

\section{Declarations}

\section{Ethics approval and consent to participate}

The study has been performed in accordance with the ethical committee of the University Hospital Center Mohamed VI Marrakech Morocco and approved it. Informed consents were obtained from family members of all patients.

\section{Consent for publication}

The family members of all patients have consent for publication.

\section{Competing interests}

The authors declare that they have no competing interest.

\section{Author details}

${ }^{1}$ Neuroscience, Pharmacology and Environment Unit (ENPE), Laboratory of Clinical and Experimental Neurosciences and Environment, faculty of Medicine and Pharmacy, Cadi Ayyad University, 4000 Marrakech, Morocco. ${ }^{2}$ Higher Instituate of Nursing Professions and Health Techniques, Ministry of Health B.P. 45000 Ouarzazate, Morocco. ${ }^{3}$ Neurology Department, University Hospital Mohammed VI, Principal‘ Avenue Ibn Sina, B.P. 2360 Marrakech, Morocco. ${ }^{4}$ Laboratory of Human Ecology, Faculty of Sciences Semlalia, Cadi Ayyad University, Avenue My Abdellah, B.P, 2390 Marrakech, Morocco.

Received: 21 November 2019 Accepted: 16 September 2021 Published online: 04 November 2021 


\section{References}

1. Preux PM. Comite de Recherche sur l'Epilepsie de I'Institut d'Epidemiologie neurologique et de Neurologie Tropicale de Limoges: questionnaire d'investigation de l'epilepsie dans les pays tropicaux. Bull Soc Pathol Exot. 2000;93:276-8.

2. Feigin VL, Nichols E, Alam T, Bannick MS, Beghi E, Blake N, et al. Global, regional, and national burden of neurological disorders, 1990-2016: a systematic analysis for the global burden of disease study 2016. Lancet Neurol. 2019:18:459-80

3. Scheffer IE, Berkovic S, Capovilla G, Connolly MB, French J, Guilhoto L, et al. ILAE classification of the epilepsies: position paper of the ILAE Commission for Classification and Terminology. Epilepsia. 2017;58:512-21.

4. Kissani N, Naji Y. The terminology of epilepsy in Arabic and its consequences in Morocco; 2019.

5. Baudouin MBBB. Les étiologies des épilepsies au service de neurologie du CHU de Marrakech; 1988.

6. Kissani N, Lengané YTM, Patterson V, Mesraoua B, Dawn E, Ozkara C, et al. Telemedicine in epilepsy: how can we improve care, teaching, and awareness? Epilepsy Behav. 2020;106854.

7. Organization WH. Epilepsy in the WHO Eastern Mediterranean region: bridging the gap. 2010. Cairo, Egypt World Heal Organ Reg Off East Mediterr Google Sch n.d.

8. Itri M, Hadj KH. Enquête épidémiologique sur les épilepsies de l'enfant. Les Cah Du Médecin. 1998;1:36-8.

9. Mebrouk Y, Chettati M, Kissani N. L'épilepsie au Maroc, réalités et perspectives. African Middle East Epilepsy J. 2012;1.

10. Houeto SE. Itineraire therapeutique des epileptiques dans I'arrondissement de djidja (departement du zou) au benin; 2005.
11. Ba-Diop A, Marin B, Druet-Cabanac M, Ngoungou EB, Newton CR, Preux P-M. Epidemiology, causes, and treatment of epilepsy in sub-Saharan Africa. Lancet Neurol. 2014;13:1029-44.

12. Espinosa-Jovel C, Toledano R, Aledo-Serrano Á, García-Morales I, Gil-Nagel A. Epidemiological profile of epilepsy in low income populations. Seizure. 2018;56:67-72.

13. Bahbiti Y, Benazzouz B, Moutaouakil F, Ouichou A, El Hessni A, Mesfioui A. Etude anthropologique et épidémiologique de l'épilepsie dans la région de Tanger (Maroc). Antropo. 2013:29:57-67.

14. Traore H, Diagana M, Debrock C, Ba A, Alqad B. Approche socioculturelle de l'epilepsie en Mauritanie. Médecine Trop. 1998:58:365-8.

15. Arib S, Kissani N. Connaissances, attitudes et pratiques traditionnelles envers l'épilepsie: enquête auprès des proches des patients; n.d.

16. Andaloussi I. Etude anthropologique et épidémiologique de l'épilepsie dans la région de Rabat-Salé-Zemmour-Zaer; 2009.

17. Adotevi F, Stephany J. Cultural perception of epilepsy in Senegal (capVert and river district)(author's transl). Med Trop Rev Du Corps Sante Colon. 1981:41:283-7.

18. Bernet-Bernady P, Tabo A, Druet-Cabanac M, Poumale F, Ndoma V. L'épilepsie et son vécu au nord-ouest de la République Centrafricaine. Médecine Trop. 1997;57:407-11.

19. Van Der Wusten PP. Les Beni Boufrah. Maroc Ed IURS Rabat FGSUA PaysBas IAVH II Rabat: Essai d'écologie sociale d'une vallée rifaine; 1983.

20. Njamnshi AK, Angwafor SA, Tabah EN, Jallon P, Muna WFT. General public knowledge, attitudes, and practices with respect to epilepsy in the Batibo Health District, Cameroon. Epilepsy Behav. 2009;14:83-8.
Ready to submit your research? Choose BMC and benefit from:

- fast, convenient online submission

- thorough peer review by experienced researchers in your field

- rapid publication on acceptance

- support for research data, including large and complex data types

- gold Open Access which fosters wider collaboration and increased citations

- maximum visibility for your research: over $100 \mathrm{M}$ website views per year

At $\mathrm{BMC}$, research is always in progress.

Learn more biomedcentral.com/submissions 